\title{
Space-selective precipitation of metal nanoparticles inside glasses
}

\section{$\operatorname{AUTHOR}(\mathrm{S})$ :}

Qiu, JR; Shirai, M; Nakaya, T; Si, JH; Jiang, XW; Zhu, CS; Hirao, K

\section{CITATION:}

Qiu, JR ... [et al]. Space-selective precipitation of metal nanoparticles inside glasses. APPLIED PHYSICS LETTERS 2002, 81(16): 3040-3042

\section{ISSUE DATE:}

2002-10-14

URL:

http://hdl.handle.net/2433/39653

\section{RIGHT:}

Copyright 2002 American Institute of Physics. This article may be downloaded for personal use only. Any other use requires prior permission of the author and the American Institute of Physics. 


\title{
Space-selective precipitation of metal nanoparticles inside glasses
}

\author{
Jianrong Qiu ${ }^{\text {a) }}$ \\ Photon Craft Project, Shanghai Institute of Optics and Fine Mechanics, Chinese Academy of Sciences, \\ and Japan Science and Technology Corporation, Keihanna-Plaza, Kyoto 619-0237, Japan
}

Mitsuru Shirai, Takayuki Nakaya, and Jinhai Si

Photon Craft Project, Japan Science and Technology Corporation, Keihanna-Plaza, Kyoto 619-0237, Japan

Xiongwei Jiang and Congshan Zhu

Photon Craft Project, Shanghai Institute of Optics and Fine Mechanics, Chinese Academy of Sciences, Shanghai 201800, China

Kazuyuki Hirao

Department of Material Chemistry, Graduate School of Engineering, Kyoto University, Sakyo-ku, Kyoto 606-8501, Japan

(Received 26 February 2002; accepted for publication 30 July 2002)

\begin{abstract}
We report the precipitation and control of metal nanoparticles inside transparent glasses. An $\mathrm{Ag}^{+}$-doped silicate glass sample was first irradiated by using an $800 \mathrm{~nm}$ femtosecond laser at room temperature and then annealed at $550{ }^{\circ} \mathrm{C}$. The area near the focal point of the laser beam became gray after laser irradiation and yellow after further annealing at $550^{\circ} \mathrm{C}$ for $10 \mathrm{~min}$. Absorption and electron spin resonance spectra of the glass sample showed that a portion of silver ions near the focused part of the laser beam inside the glass were reduced to silver atoms after the laser irradiation. These silver atoms aggregated to form nanoparticles after further annealing at temperatures above $500^{\circ} \mathrm{C}$. A mechanism is suggested that consists of multiphoton reduction, which is induced by the fundamental light of the laser beam and supercontinuum white light, and diffusion of silver atoms driven by heat energy to form nanoparticles. The observed phenomenon may have promising applications for the fabrication of three-dimensional multicolored images inside a transparent material and for integrative micro-optical switches. (C) 2002 American Institute of Physics. [DOI: 10.1063/1.1509095]
\end{abstract}

Noble metal nanoparticle-doped glasses exhibit large third-order nonlinear susceptibility and ultrafast nonlinear response. ${ }^{1,2}$ They are expected to be promising materials for an ultrafast all-optical switch in the $\mathrm{THz}$ region. ${ }^{3}$ There have been extensive studies conducted on the fabrication and characterization of metal nanoparticle-doped glasses. ${ }^{4-11}$ The fabrication methods discussed so far include traditional melting and annealing, sol gel, chemical vapor deposition, sputtering, ion exchange, and ion implantation. ${ }^{4-11}$ Hofmeister et al. ${ }^{9}$ and Chen et al. ${ }^{10}$ have succeeded in the synthesis of nanosized silver particles via electron-beam irradiation, $\mathrm{x}$-ray irradiation, and successive annealing. Recently, Valentin et al. ${ }^{11}$ demonstrated complete control over the metal cluster density, average size, and size distribution of copper by room-temperature $\mathrm{MeV}$ ion irradiation. Of the aforementioned fabrication processes, ion exchange and ion implantation can realize space-selective precipitation of nanoparticles. However, both the composition of the glass matrix and the nanoparticle-precipitated area after further treatment are restricted in the ion-exchange method. In the case of ion implantation, the glass matrix is usually damaged severely and some impurities may be induced. In addition, both the size and space distribution of nanoparticles are broad from the surface to the inside of the glass sample.

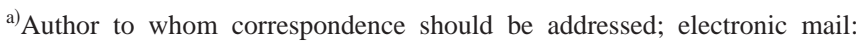
jrq@photon.jst.go.jp
}

Recently, an ultrashort pulsed laser has been used as a powerful tool to make microscopic modifications to transparent materials. ${ }^{12-19}$ The reason for using this laser is that its electric field intensity can reach $100 \mathrm{TW} / \mathrm{cm}^{2}$, which is sufficient for inducing nonlinear optical effects in materials by the use of a focusing lens when the pulse width is $100 \mathrm{fs}$ and the pulse energy is $1 \mu \mathrm{J}$. The photoinduced reaction is expected to occur only near the focused part of the laser beam due to nonlinear optical processes.

Stookey ${ }^{20}$ developed photosensitive glasses early in the 1950's. These glasses contain noble metal photosensitive ions such as $\mathrm{Ag}^{+}$and $\mathrm{Au}^{+}$together with $\mathrm{Ce}^{3+}$, which act as a sensitizer. After the irradiation by $\mathrm{UV}$ light, $\mathrm{Ce}^{3+}$ releases an electron to form $\mathrm{Ce}^{4+}$, while $\mathrm{Ag}^{+}$or $\mathrm{Au}^{+}$captures the electron to form an $\mathrm{Ag}$ or $\mathrm{Au}$ atom. After subsequent heat treatment, crystallites, e.g., $\mathrm{LiF}$ and $\mathrm{Li}_{2} \mathrm{SiO}_{5}$, precipitate in the UV-irradiated area due to the nucleation by the metal cluster or colloids. It is possible to fabricate a twodimensional designed structure when a mask is used. However, it is impossible to fabricate a three-dimensional modulated structure inside glasses since the UV light resonates with the absorption band of $\mathrm{Ce}^{3+}$.

In this letter, we report the space-selective precipitation and control of noble metal nanoparticles in transparent materials. We observed space-selective photoreduction of the $\mathrm{Ag}^{+}$ion to the $\mathrm{Ag}$ atom in a silicate glass by focusing $120 \mathrm{fs}$ laser pulses from a regeneratively amplified Ti: Sapphire la- 


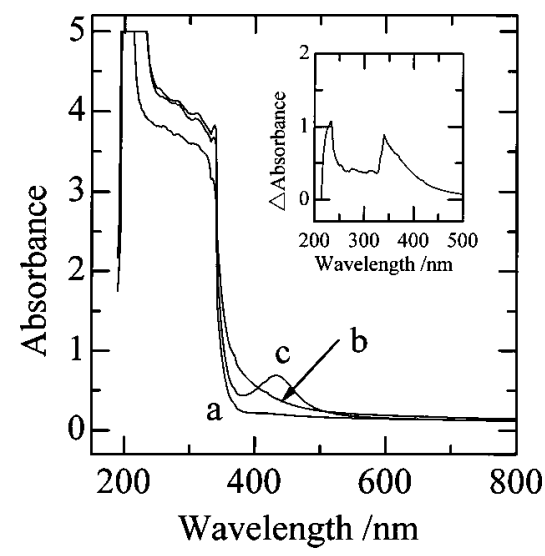

FIG. 1. Absorption spectra of the $\mathrm{Ag}^{+}$-doped silicate glass before (a) and after (b) the femtosecond laser irradiation, and (c) after further annealing at $550{ }^{\circ} \mathrm{C}$ for $10 \mathrm{~min}$. The inset of Fig. 1 shows the difference in absorption spectra of the glass sample before and after the femtosecond laser irradiation.

ser through a microscope objective lens. Absorption and electron spin resonance spectra were measured for the glass sample before and after femtosecond laser irradiation, as well as after further annealing at $550^{\circ} \mathrm{C}$. The mechanism of the occurrence of the phenomenon is also discussed.

The glass composition of the $\mathrm{Ag}^{+}$-doped silicate glass sample used in this study was $0.1 \mathrm{Ag}_{2} \mathrm{O} \cdot 70 \mathrm{SiO}_{2} \cdot 10 \mathrm{CaO}$ - $20 \mathrm{Na}_{2} \mathrm{O}$ (mol \%). Reagent grade $\mathrm{SiO}_{2}, \mathrm{CaCO}_{3}, \mathrm{Na}_{2} \mathrm{CO}_{3}$, and $\mathrm{Ag}_{2} \mathrm{O}$ were used as starting materials. Details of the glass-preparation procedure have been described elsewhere. ${ }^{18}$

A regeneratively amplified $800 \mathrm{~nm}$ Ti: Sapphire laser that emits $120 \mathrm{fs}, 1 \mathrm{kHz}$, mode-locked pulses was used in our experiments. The laser beam with an average power of 400 $\mathrm{mW}$ was focused by a $10 \times$ objective lens with a numerical aperture of 0.30 on the interior of the glass sample with the help of an XYZ stage. The spot size (diameter) of the laser beam was estimated to be $10 \mu \mathrm{m}$.

Absorption spectra of the glass samples were measured by a spectrophotometer (JASCO V-570). Electron spin resonance (ESR) measurements were carried out at $X$-band frequency $(9.8 \mathrm{GHz})$ by an ESR spectrophotometer (JEOLFE3X). The microwave power, time constant, modulation amplitude, and sweep time were $1 \mathrm{~mW}, 0.03 \mathrm{~s}, 1 \times 100$, and $4 \mathrm{~cm} / \mathrm{min}$, respectively. All of the experiments were carried out at room temperature.

After irradiation by the focused infrared femtosecond laser on each spot for $1 / 63 \mathrm{~s}$, a $10 \mu \mathrm{m}$ spot was formed in the focused area of the laser beam in the $\mathrm{Ag}^{+}$-doped glass sample. In addition, a gray-colored area with a diameter of about $40 \mu \mathrm{m}$ was observed around the spot. The length of the induced structure along the axis of the laser beam was about $1.5 \mathrm{~mm}$ as observed by optical microscope. To measure the absorption spectrum of the glass sample after laser irradiation, we created a "damaged" plane of $3.0 \times 3.0 \mathrm{~mm}^{2}$ inside the glass sample, which consisted of damaged lines at intervals of $10 \mu \mathrm{m}$ by scanning the laser beam at a rate of 1 $\mathrm{mm} / \mathrm{s}$. The glass sample was further annealed at $550^{\circ} \mathrm{C}$ for $10 \mathrm{~min}$. The laser-irradiated part became yellow after the heat treatment.

Figure 1 shows the absorption spectra of the glass Downloaded 30 May 2007 to 130.54 .110 .22 . Redistribution subject

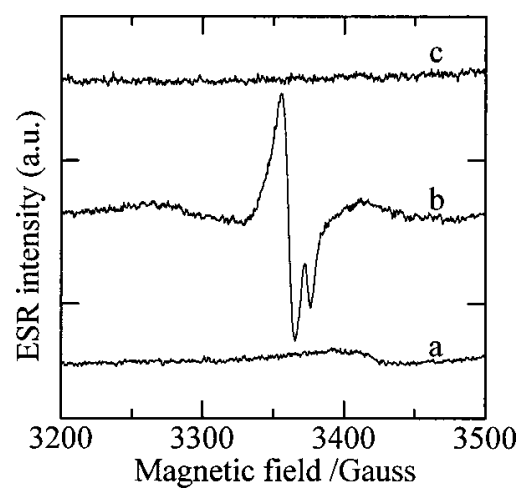

FIG. 2. ESR spectra of the glass sample before (a) and after (b) the femtosecond laser irradiation, and (c) after further annealing at $550^{\circ} \mathrm{C}$ for $10 \mathrm{~min}$.

sample before [Fig. 1(a)] and after [Fig. 1(b)] femtosecond laser irradiation, and [Fig. 1(c)] after further annealing at $550^{\circ} \mathrm{C}$ for $10 \mathrm{~min}$. No apparent absorption was observed for the unirradiated glass sample in the wavelength region from 600 to $800 \mathrm{~nm}$, while there was an apparent increase in the absorbance in the wavelength region from 220 to $600 \mathrm{~nm}$ in the irradiated region. The inset of Fig. 1 shows the difference in absorption spectra of the glass sample before and after the femtosecond laser irradiation. The absorption peaks at about 240 and $350 \mathrm{~nm}$ can be assigned to the atomic silver and hole trap centers at nonbridging oxygen near $\mathrm{Ag}^{+}$ions, respectively. ${ }^{21}$ Therefore, an electron was driven out from the $2 p$ orbital of a nonbridging atom near the $\mathrm{Ag}^{+}$ions after femtosecond laser irradiation, while $\mathrm{Ag}^{+}$captured the electron to form an $\mathrm{Ag}$ atom. Figure 1 also shows that a new peak appeared at $450 \mathrm{~nm}$ in the absorption of the glass sample after further annealing at $550{ }^{\circ} \mathrm{C}$. The peak can be assigned to the absorption due to the surface plasmon of the silver nanoparticle. ${ }^{22}$ Preliminary observation with a JEM2010FEF transmission electron microscope also showed that spherical particles with sizes ranging from 1 to $8 \mathrm{~nm}$ precipitated in the sample. The photon-reduced $\mathrm{Ag}$ atoms aggregated to form nanoparticles after the heat treatment. An unirradiated glass sample precipitates nanoparticles only at temperatures above $600{ }^{\circ} \mathrm{C}$. Therefore, we suggest that the neutralized $\mathrm{Ag}$ promotes nucleation. Femtosecond laser irradiation can be used to separate and control the nucleation and growth processes.

Figure 2 shows the ESR spectra of the glass sample before [Fig. 2(a)] and after [Fig. 2(b)] the femtosecond laser irradiation at room temperature, and [Fig. 2(c)] after further annealing at $550{ }^{\circ} \mathrm{C}$ for $10 \mathrm{~min}$. No apparent signal was detected in the unirradiated glass sample, while the spectrum of the glass sample after femtosecond laser irradiation showed a broad signal at $g \sim 2.10$ and two signals at $g \sim 2.00$. The broad signal at 2.10 may be due to the $\mathrm{Ag}$ atom, ${ }^{23}$ while two signals at $g \sim 2.00$ can be assigned to hole trap centers $(\mathrm{HC})$, e.g., $\mathrm{HC}_{1}$ and $\mathrm{HC}_{2} .{ }^{24}$ The $\mathrm{HC}_{1}$ and $\mathrm{HC}_{2}$ are holes trapped at the nonbridging oxygen in the $\mathrm{SiO}_{4}$ polyhedron with two and three nonbridging oxygen, respectively.

We carried out several experiments to clarify the mechanism of the formation of induced structures after femtosecond laser irradiation. We observed that the size of the nanoparticle-precipitated area is the same as the area in which supercontinuum white light was observed during fem-
o AlP license or copyright, see http://apl.aip.org/apl/copyright.jsp 


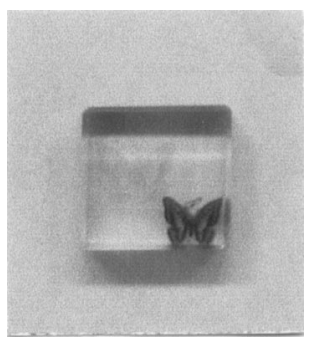

FIG. 3. Photograph of butterflies drawn inside the glass sample by using the femtosecond laser: Gray color (after femtosecond laser irradiation, at the right and the lower part) and yellow color (after femtosecond laser irradiation and further heat treatment at $550{ }^{\circ} \mathrm{C}$ for $10 \mathrm{~min}$, at left and the upper part).

tosecond laser irradiation and is also the same as the dark area induced by femtosecond laser irradiation. There is now a consensus that multiphoton absorption due to the fundamental wave and supercontinuum white light, which arises from self-phase modulation of the laser beam, plays an important role in the formation of induced structures. In the present case, electrons are driven out from the $2 p$ orbital of the nonbridging oxygen in the $\mathrm{SiO}_{4}$ polyhedron via the multiphoton absorption of the incident photon. $\mathrm{Ag}^{+}$captures the electron to form an $\mathrm{Ag}$ atom. We also confirmed that the length of the femtosecond laser induced structure was directly proportional to the square root of the average power of the laser beam. This result is in good agreement with the theory of Zverev et al., ${ }^{25}$ if we assume that the length of the induced structure is directly proportional to the length of the filament, which is due to the balance between self-focusing arising from an increase in the refractive index and selfdefocusing arising from plasma formation. We have also confirmed that no change is observed in the absorption spectrum of the nanoparticle-precipitated glass sample after heat treatment at room temperature even for 6 months, indicating that the precipitated nanoparticles are stable at room temperature. In addition, we have also realized the spaceselective precipitation of gold and other metal nanoparticles. Our results showed that the color of the gold nanoparticleprecipitated area changed from violet to red when the power density of the laser increased from $10^{12}$ to $10^{15} \mathrm{~W} / \mathrm{cm}^{2}$. The different color is due to the different size of gold nanoparticle. The details will be reported elsewhere.

In summary, we have observed space-selective precipitation and control of noble metal nanoparticles in transparent materials by a focused infrared femtosecond pulsed laser irradiation at room temperature and further annealing at high temperature. Nonbridging oxygen is suggested to act as HCs while the $\mathrm{Ag}^{+}$ion acts as an electron-trapping center, thus resulting in the reduction of $\mathrm{Ag}^{+}$ions to $\mathrm{Ag}$ atoms. White light supercontinuum plays an important role in the formation of $\mathrm{Ag}$ atoms. Since the focused-on area becomes gray after laser irradiation and then becomes yellow after heat treatment, it is possible to draw a three-dimensional multicolored image inside the transparent and colorless glass sample, as shown in Fig. 3. The length of the induced structure is directly proportional to the square root of the average power of the laser beam; therefore, it is possible to control the longitudinal spreading of the structurally changed area from several hundred nanometers to several millimeters by selecting the appropriate irradiation condition. Our results demonstrated the possibility of space-selective precipitation of nanoparticles in a micrometer-small dimension inside a transparent material by using a focused nonresonant femtosecond pulsed laser and heat treatment. This technique will be useful in the fabrication of three-dimensional multicolored industrial art objects, optical memory, and integrative waveguidelike optical switches with ultrafast nonlinear response.

One of the authors (J.Q.) would like to acknowledge the financial support provided by the National Natural Science Foundation of China (No. 50125208).

${ }^{1}$ D. Ricard, P. Roussignol, and C. Flytznis, Opt. Lett. 10, 511 (1985).

${ }^{2}$ F. Hache, D. Ricard, and C. Flytzanis, J. Opt. Soc. Am. B 3, 1647 (1986).

${ }^{3}$ H. Inouye, K. Tanaka, I. Tanahashi, and K. Hirao, J. Phys. Soc. Jpn. 68, 3810 (1999).

${ }^{4}$ Y. Hamana, N. Hayashi, A. Nakamura, and S. Omi, J. Lumin. 87, 859 (2000).

${ }^{5}$ M. Ferrari, L. M. Gratton, A. Maddalena, M. Montagna, and C. Tosello, J. Non-Cryst. Solids 191, 101 (1995).

${ }^{6}$ Y. Maeda, Phys. Rev. B 51, 1658 (1995).

${ }^{7}$ M. Dublel and G. Mosel, Jpn. J. Appl. Phys., Part 1 33, 5892 (1994).

${ }^{8}$ F. Gonella, G. Mattei, P. Mazzoldi, C. Sada, G. Battaglin, and E. Cattaruzza, Appl. Phys. Lett. 75, 55 (1999).

${ }^{9}$ H. Hofmeister, S. Thiel, M. Dubiel, and E. Schurig, Appl. Phys. Lett. 70, 1694 (1997).

${ }^{10}$ S. Chen, T. Akai, K. Kadono, and T. Yazawa, Appl. Phys. Lett. 79, 3687 (2001).

${ }^{11}$ E. Valentin, H. Bernas, C. Ricolleau, and F. Creuzet, Phys. Rev. Lett. 86, 99 (2001).

${ }^{12}$ K. M. Davis, K. Miura, N. Sugimoto, and K. Hirao, Opt. Lett. 21, 1729 (1996).

${ }^{13}$ E. N. Glezer, M. Milosavljevic, L. Huang, R. J. Finalay, T.-H. Her, J. P. Callan, and E. Mazur, Opt. Lett. 21, 2023 (1996).

${ }^{14}$ K. Miura, J. Qiu, H. Inouye, T. Mitsuyu, and K. Hirao, Appl. Phys. Lett. 71, 3329 (1997)

${ }^{15}$ J. Qiu, K. Miura, H. Inouye, Y. Kondo, T. Mitsuyu, and K. Hirao, Appl. Phys. Lett. 73, 1763 (1998)

${ }^{16}$ J. Qiu, K. Miura, and K. Hirao, Jpn. J. Appl. Phys., Part 1 37, 2263 (1998).

${ }^{17}$ J. Qiu, K. Miura, T. Suzuki, T. Mitsuyu, and K. Hirao, Appl. Phys. Lett. 74, 10 (1999).

${ }^{18}$ J. Qiu, C. Zhu, T. Nakaya, J. Si, F. Ogura, K. Kojima, and K. Hirao, Appl. Phys. Lett. 79, 3567 (2001).

${ }^{19}$ H. Sun, Y. Xu, S. Joudkazis, K. Sun, M. Watanabe, J. Nishii, S. Matsuo, and H. Misawa, Opt. Lett. 20, 325 (2001).

${ }^{20}$ S. D. Stookey, Ind. Eng. Chem. 45, 115 (1953).

${ }^{21}$ M. Tashiro and N. Soga, Kogyo Kagaku Zasshi 65, 342 (1962).

${ }^{22}$ I. Tanahashi, M. Yoshida, Y. Manabe, and T. Tohda, J. Mater. Res. 10, 362 (1995).

${ }^{23}$ H. Imagawa, J. Non-Cryst. Solids 1, 262 (1969).

${ }^{24}$ J. W. H. Schreurs, J. Chem. Phys. 47, 818 (1967).

${ }^{25}$ G. M. Zverev and V. A. Pashkov, Sov. Phys. JETP 30, 616 (1970). 